\title{
BCG vaccination as a cause of osteomyelitis and subcutaneous abscess
}

\author{
H PELTOLA, I SALMI, V VAHVANEN, AND J AHLQVIST \\ Children's Hospital, University of Helsinki; Departments of Paediatrics, Surgery and Pathology, Aurora \\ Hospital; and Orthopaedic Hospital of The Invalid Foundation, Helsinki, Finland
}

SUMmARY Ten patients with osteomyelitis and three with a subcutaneous abscess, all caused by BCG vaccination, are described. All patients were less than 3 years old and had as newborns been vaccinated intracutaneously in the left gluteal or hip area. Pain, limping, or a slightly tender subcutaneous induration were the primary symptoms. The sites of predilection of osteomyelitis were the metaphysis or epiphysis of the femur, these being affected in five out of 10 cases. All three subcutaneous abscesses were in the thoracic region.

Prolonged (up to 30 months) combined tuberculostatic medication, in addition to appropriate surgical procedures, resulted in healing, but two cases of arthritis and two of secondary abscesses developed. In addition, sequestrectomy and two late operations, for coxa valga and hip subluxation, were deemed to be necessary. Radiographs showed femoral overgrowth of up to $1 \mathrm{~cm}$ in two symptomless patients three to seven years after the first discharge. We conclude that the benefits of BCG vaccination should be weighed against the risk of complications, especially in countries with a low incidence of tuberculosis.

Osteomyelitis, also called osteitis, caused by neonatal $\mathrm{BCG}$ vaccination is a well known entity among bone infections in Scandinavia and elsewhere in Europe, ${ }^{1-3}$ where for decades this immunisation has been practised routinely. Despite controversy about the efficacy of BCG vaccination, ${ }^{45}$ there is general consensus, for example, in Finland, that the disappearance of meningeal, miliary, and other serious forms of childhood tuberculosis can be attributed chiefly to neonatal immunisation. On the other hand, the benefits of BCG vaccination have to be weighed against the complications, one of which is iatrogenic osteomyelitis.

During the 10 year period $1970-9$ we found in our hospital 10 cases of mycobacterial osteomyelitis and three further cases of subcutaneous abscess which were probably caused by BCG vaccination. As these patients constituted a very special group of orthopaedic infections, we present them all in our clinical review.

\section{Materials and methods}

The series comprised all the patients diagnosed in the 1970s at Aurora Hospital, Helsinki (500 000 inhabitants). The vaccination status of each patient was checked from the official reports of the maternity hospitals and child health centres where the vaccine (altogether $0.2 \mathrm{ml}$ in two sites until 1977; $0.1 \mathrm{ml}$ from 1978 on) had been injected intracutaneously into the left gluteal region. The vaccine contained 1-1.5 $\times$ $10^{6}$ viable bacteria per $\mathrm{ml}$. Scar formation was confirmed.

The histological diagnosis ${ }^{3}$ was considered to be suggestive when the pathologist recognised in surgical biopsy specimens non-fibrotic ('soft'), well vascularised granulation tissue, and in addition to other inflammatory cells, foci of macrophages, small epithelioid cell granulomata and (sometimes) multinucleated giant cells. Some granulomata were necrotic without being caseous, and some necroses contained numerous neutrophils. Acid-fast bacilli were occasionally found by auramin-rhodamine staining.

Mycobacterial culture was attempted in all cases. If it proved positive, the bacteria were identified ${ }^{6}$ at the National Public Health Institute, Helsinki (Dr Eljas Brander) by sensitivity tests and by determination of virulence in guinea pigs. The tuberculin test was done routinely by the Mantoux technique.

All but one patient, who could not be traced, were 
followed regularly for several years. On average, the last follow up took place $3 \cdot 2$ years after discharge from hospital.

\section{Results}

The osteomyelitis series comprised six boys and four girls. Two subcutaneous abscess patients were girls and one was a boy (Table). The age range in the osteomyelitis group was 6-31 months and in the subcutaneous abscess group 8-16 months. All had been vaccinated with BCG, and 8 children $(62 \%)$ showed a positive skin reaction to a tuberculin dose of $1.0 \mathrm{TU}$ ( 7 cases) or $0 \cdot 1 \mathrm{TU}$ (one case). There was only one known contact with tuberculosis (case 4 in Table, see below).

Site and duration of symptoms. Typically, the onset of the disease was insidious, symptoms appearing 6-31 months after vaccination (Table). The symptoms that led the parents to seek medical advice were pain, a tender or painless induration on the rib, limping, or inability to walk. As a rule, the symptoms had lasted for several weeks.

In no less than five osteomyelitis patients the proximal or distal-epiphyseal region of the femur was affected, the other sites being the acetabulum, the calcaneum, the (fifth) rib and the vertebrae (Table). As to the subcutaneous abscess patients, the presenting lesion was a slightly tender induration about half an inch in diameter in the pectoral area or on the sternum.

Diagnosis. The patients were only mildly ill. The local process with tenderness and swelling mimicked classical osteomyelitis so closely that, except in the cases with affected ribs or with subcutaneous abscess, antimicrobial treatment with penicillin $G$, or staphylococcal penicillin, lincomycin, or clindamycin was instituted even though the erythrocyte sedimentation rate (ESR) was seldom higher than $20 \mathrm{~mm}$ in the first hour and there were no other signs of bacterial infection. Nonspecific $x$ ray changes ${ }^{78}$ were detectable in 6 osteomyelitis cases. The values of $C$ reactive protein were low (less than $20 \mathrm{mg} / \mathrm{l}$ ) in the four cases determined.

Apart from cases 2 and 5 (Table) who had such characteristic rib lesions ${ }^{1}$ that the ribs were resected without delay, the first hint of BCG osteomyelitis was the lack of response to conventional antimicrobial treatment. Within two months such foci were opened surgically, samples were taken for histology, and a correct diagnosis was finally reached.

The subcutaneous indurations were removed in all three cases. In one, the diagnosis was based on $x$ ray findings (showing no bone lesion) and biopsy (Table).

Although the suspicion of mycobacterial infection was confirmed immediately by positive acid fast staining in four patients, histology ${ }^{3}$ was the key to diagnosis, being highly suggestive in all but two cases, where the sample obtained was not informative. Later cultures yielded mycobacteria on 6 occasions. The importance of identifying the BCG strain $^{6}$ is emphasised by case 4 (Table); a grandfather had had pulmonary tuberculosis the previous year, but the BCG strain could be identified in the bone lesion of the patient.

In one child (case 10, Table) diagnosis was based on circumstantial evidence only. Back pain, which had been present for two months before admission, appeared 31 months after vaccination; the course was insidious, and there was no fever. The maximal ESR observed was $33 \mathrm{~mm}$ in the first hour, and chest $x$ ray showed no signs of tuberculosis. However, changes due to osteomyelitis were seen in vertebrae IV-V, but the biopsy was uninformative; staining and culture proved negative. Tuberculostatic medication was instituted on clinical grounds, and the boy was discharged symptom free 62 days later. There was no recurrence during a period of five years, and the $x$ ray picture became normal.

Medication and hospitalisation. With minor modifications drugs were administered as follows. If a clear increase in liver enzymes (well above 100 SF units) was observed or adverse reactions were intolerable, the first alternative was replaced by the second alternative.

1 First two months, triple medication: streptomycin (SM) $15 \mathrm{mg} / \mathrm{kg} /$ day plus pyrazinamide (PZA) $25 \mathrm{mg} / \mathrm{kg} /$ day or, from 1974 , rifampicin (RMP) $20 \mathrm{mg} / \mathrm{kg} /$ day or ethionamide (EA) 16 $\mathrm{mg} / \mathrm{kg} /$ day plus isoniazide (INH) $15-20$ $\mathrm{mg} / \mathrm{kg} /$ day.

2 Next four months, dual medication: PZA 25 $\mathrm{mg} / \mathrm{kg} /$ day or RMP $20 \mathrm{mg} / \mathrm{kg} /$ day, or EA 16 $\mathrm{mg} / \mathrm{kg} /$ day plus INH $10-15 \mathrm{mg} / \mathrm{kg} /$ day.

3 Up to a total period of 10-24 months: INH $10-15 \mathrm{mg} / \mathrm{kg} /$ day.

In general, no serious reactions occurred and no difficulties in administration were encountered. One child was treated for 30 months because of secondary abscess formation. The average stay in hospital was three months (93 days). The longest stay in the ward, 342 days, was required for treatment of the sequestrum of the femur (case 9). Case 10, with lumbar involvement, was treated in a plaster bed for two months. 


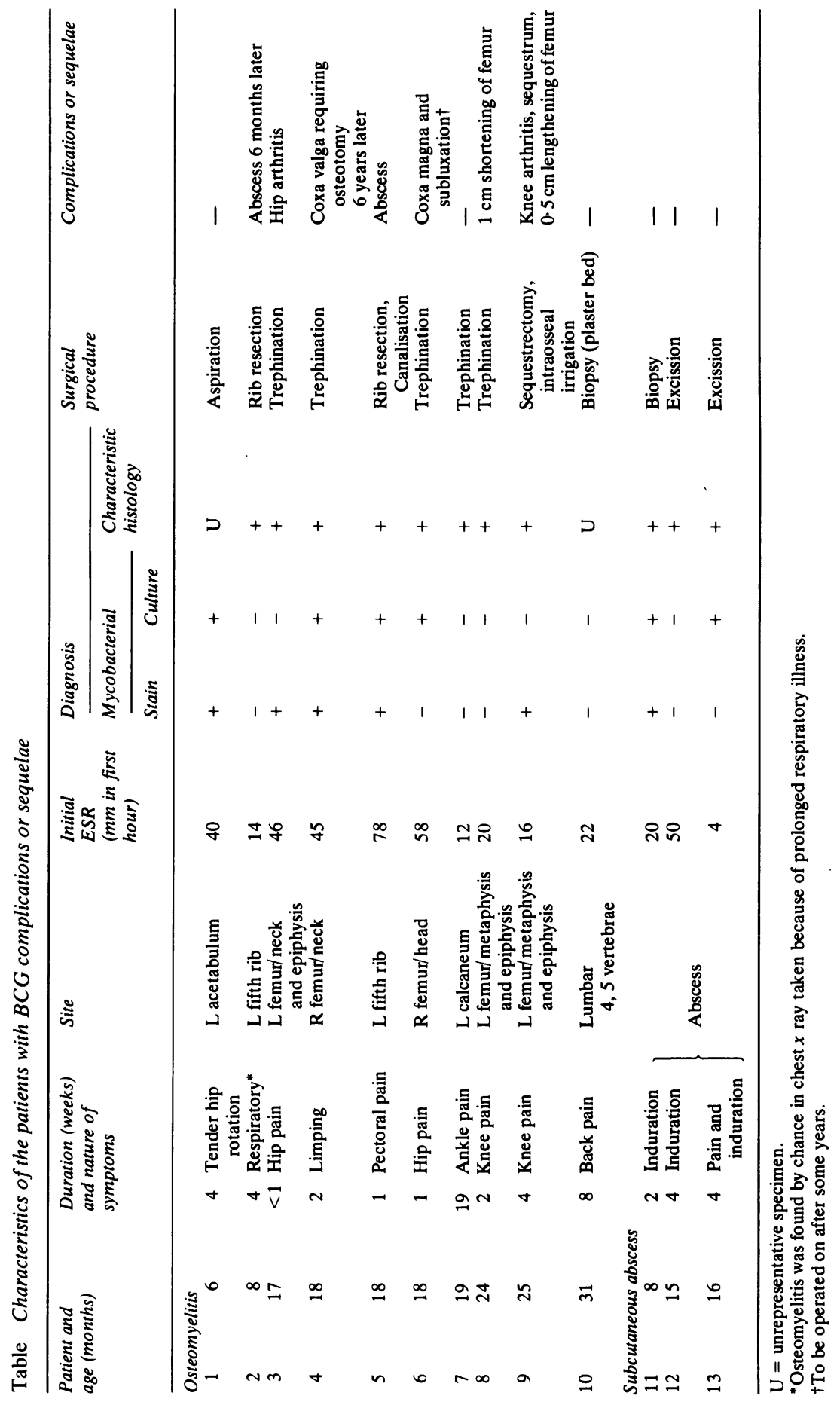


Complications and sequelae. (Table). Complications developed in seven of the osteomyelitis patients. In two cases secondary abscess formation developed. Arthritis of the hip (case 3) and of the knee (case 9), however, caused greater concern; the latter required sequestrectomy. One patient (case 4) developed coxa valga, which was corrected six years later by osteotomy. Late operation is planned in case 6 , in whom coxa magna with subluxation has developed.

\section{Discussion}

A basic question, when dealing with a tuberculous process, is whether the infection is caused by primary (human or bovine) infection or by BCG vaccination. Clinical, microbiological, and epidemiological data support the view that our cases were all iatrogenic.

An active eradication programme ${ }^{9}$ has virtually eliminated Mycobacterium bovis from Finland; since 1976 no case has been reported (Dr E Brander, personal communication, 1983). Therefore, it is unlikely that $M$ bovis could have caused the four cases of osteomyelitis where microbiological evidence was not obtained.

All children had received BCG vaccination 6-31 months before admission, and in all 6 cases with a positive culture the strains were identified as BCG. Apart from case 10, all the lesions were found in bones other than the spine, the characteristic site of $M$ tuberculosis infection (the spine is affected in approximately $50 \%$ of cases of skeletal tuberculosis, ${ }^{10}$ and in one series $61 \%$ of 426 patients with orthopaedic tuberculosis had spondylitis). ${ }^{11}$ Moreover, spinal tuberculosis is typically a disease of adults,${ }^{10}$ as indicated by the fact that in the age group $0-14$ years, only four cases of tuberculous spondylitis were reported in Finland (population 4.8 million) during 1977-9 (National Board of Health Statistics, 1982). In 1979 even pulmonary tuberculosis had a total incidence of only 39/100 $000 .^{12}$

At least two factors delayed the prompt diagnosis of BCG osteomyelitis. Firstly, the lesions are uncommon: in the 1970s the number of cases of BCG osteomyelitis was estimated to be 46 in Finland, 35 in Sweden, and 0.6 in 8 other European countries per million newborn vaccinated. ${ }^{1}$ Secondly, the symptoms developed slowly, the primary course was fairly benign, the $x$ ray changes (when detectable) were not diagnostic, ${ }^{78}$ and the ESR and CRP were only moderately, if at all, raised. Virtually all patients had primarily received antimicrobials without tuberculostatic activity.

Some characteristics were, however, typical and should be helpful in the differential diagnosis. All the children had been vaccinated less than three years earlier. Most of the lesions occurred in the sternum, costae or metaphyseal regions of the long bones ${ }^{12}$ ( $70 \%$ in this series) and tended to appear on the same side of the body as the vaccination $(70 \%)$. The clinical picture was less acute than, say, in staphylococcal or streptococcal osteomyelitis, as indicated by the rather low ESR and CRP values. The normal CRP values in particular seemed to afford a clue for distinguishing BCG-osteomyelitis from osteomyelitis due to other causes. ${ }^{13}$

No satisfactory explanation can be proffered for the high incidence of these complications in Finland. The Gothenburg strain of the vaccine produced in Sweden was used till 1971, when production was transferred to Copenhagen. Vaccine was purchased from Denmark in 1971-7 (thereafter from the United Kingdom), and during this period the frequency of BCG-osteomyelitis increased, suggesting some change in the virulence of the vaccine. This hypothesis is supported partly by a study on the reactogenicity of different BCG strains, ${ }^{14}$ but as yet the hypothesis has never been proved microbiologically. Whether any importance should be attached to some technical problems in vaccination, or to the vaccination site (the gluteal region is seldom used outside Scandinavia) are questions still to be answered. Halving the dose (from 0.2 to $0.1 \mathrm{ml}$ ) and changing the manufacturer in 1978 have not resolved the problem compietely.

Complications of BCG vaccination have caused notable changes in immunisation policy in Scandinavia. When calculations showed that routine vaccination prevents 6 to 17 cases a year of other types of tuberculosis but causes 20 cases of BCG osteomyelitis (approximately one case per $3000^{2}-5000^{15}$ vaccinations), routine neonatal BCG vaccination was abandoned in Sweden in $1975 .{ }^{2}$ Cases of tuberculous meningitis have, however, reappeared after an interval of 25 years. ${ }^{16}$ The same experience has been noted in Spain where routine $B C G$ vaccination (at least in the Barcelona area) was stopped in $1974 .{ }^{17}$ As a consequence, 7 cases of tuberculous meningitis in children have been described recently. ${ }^{18}$ In Finland, where the risk of tuberculosis has been continuously higher than in Sweden, routine neonatal BCG vaccination is still practised. We think this is a wise policy.

We thank Dr Eljas Brander, National Public Health Institute, Helsinki, in whose laboratory the cultures were carried out. The study was supported in part by a grant from E R Squibb \& Sons Ltd.

\section{References}

1 Wasz-Höckert O, Backman A, Lotte A, et al. Osteitis caused by BCG vaccination of newborn. Bull Int Union Tuberc 1979;54:325. 
2 Böttiger M, Romanus V, de Verdier C, Boman G. Osteitis and other complications caused by generalized BCG-itis. Experiences in Sweden. Acta Paediatr Scand 1982;71:471-8.

3 Schopfer K, Matter L, Brunner C, Pagon S, Stanisic M, Baerlocher K. BCG osteomyelitis. Case report and review. Helv Paediatr Acta 1982;37:73-81.

4 BCG vaccination in the newborn and young infants. Weekly Epidemiological Record 1980;55:1-3.

5 Tuberculosis prevention trial, Madras. Trial of BCG vaccines in South India for tuberculosis prevention. Indian J Med Res 1979;70:349-63.

- Yates MD, Collins CH. Identification of tubercle bacilli. Ann Microbiol 1979;130B:13-9.

7 Erikson U, Hielmstedt $\AA$. Roentgenologic aspects of BCGosteomyelitis. Radiology 1971;101:575-8.

8 Mortensson W, Eklöf O, Jorulf $\mathrm{H}$. Radiologic aspects of BCG osteomyelitis in infants and children. Acta Radiol [Diagn] (Stockh) 1976;17:845-55.

- Wasz-Höckert O, Vuorinen R, Brander E. Erfolgereiche staatliche Massnahmen gegen Rinder- und andere Haustiertuberkulose in Finnland (Eng. abstract) Ann Hyg Med Social Fenn 1962;1:94-104.

10 Davidson PT, Horowitz I. Skeletal tuberculosis: a review in patient presentations and discussion. Am J Med 1970;48:77-84.

11 Griffiths DLI. Orthopaedic tuberculosis in the tropics. Trop Doctor 1974;4:158-68.
12 Yearbook of National Board of Health 1979-1980. Official statistics of Finland. Helsinki: 1981.

13 Peltola H, Räsänen JA. Quantitative C-reactive protein in relation to erythrocyte sedimentation rate, fever, and duration of antimicrobial therapy in bacteraemic diseases of childhood. $J$ Infection 1982;5:257-67.

${ }^{14}$ Koivisto M, Brander E, Hakosalo J, Wasz-Höckert O. A comparative study of three BCG vaccines. Duodecim 1974;90:1717-22.

15 Riska N. Tuberculin testing and BCG. Finska Läkaresällskapets Handlingar 1979;123:183-9.

16 Kindmark C-O, Friman G, Nôu E. Reappearance of childhood tuberculous meningitis in Sweden. Scand $J$ Infect Dis 1982;14:151-2.

17 Department de Sanitat i Seguretat Social. Direcció general de promoció de la salut. Manual de prevenció $i$ control de la tuberculosi. Barcelona: 1981.

${ }^{18}$ Carreras Batlle N, Puig de la Capilla I, Vila Cots J. Meningitis tuberculosa: a propósit de 7 casos. Sant Pau 1982;3:158-61.

Correspondence to and reprints from Dr $\mathrm{H}$ Peltola, National Public Health Institute, Mannerheimintie 166, SF-00280 Helsinki 28, Finland.

Received 26 August 1983 